\title{
REMEDY FOR WORK STRESS: THE IMPACT AND MECHANISM OF ETHICAL LEADERSHIP
}

\author{
Hao Zhou, Maozhu Jin, Qian Ma \\ Business School, Sichuan University, Chengdu, China
}

\section{SUMMARY}

Aim: Ethical leadership was characterized by integrity, honesty and trustworthiness. The purpose of this study was to investigate whether and how ethical leadership relates to employees' work stress, specifically the mediating role of leader-member exchange (LMX), which referred to the dyadic exchange relationships between supervisors and subordinates within the workplace.

Methods: Cross-sectional data for ethical leadership, LMX, perception of work stress, and control variables were collected through the questionnaire that included 47 multiple-choice questions and 3 open-ended questions. Double-blind design was adopted in this study. Hypotheses were tested by hierarchical regression analysis.

Results: 203 first-line technical support employees from a communications enterprise participated in this study (return ratio 98.5\%). Of the respondents, $58.6 \%$ were male, average age was 35.24 years, average years in the company and in current position were 13.67 years and 11.12 years, respectively. Results revealed that the subjective evaluation of supervisors' ethical leadership was negatively related to employees' perception of work stress $(\beta=-0.24, p<0.001)$, and this relationship was completely mediated by LMX.

Conclusions: Through establishing high-quality LMX, ethical leadership played an important role in relieving employees' perception of work stress.

Key words: work stress, ethical leadership, leader-member exchange

Address for correspondence: Maozhu Jin, No.24 South Section 1, Yihuan Road, Chengdu, China. E-mail: jinmaozhu@scu.edu.cn

\section{INTRODUCTION}

Stress is a major cause of health problems throughout the world. For most individuals, work is an important part of life and everyday living (1). Thus, it is reasonable to believe that work stress plays a major role in individual stress. According to the global report from Regus in 2009, work stress affected more than half of working people (58.3\%) all over the world (2).

Work stress was defined as an individual's psychological response to a situation in which there is something at stake or exceeds individual's capacity or resources (3). Numerous findings in various organizational settings have demonstrated that work stress was negatively related to employee health. For example, Tang et al. (4) found that work stress was negatively related to employee mental health $(r=-0.26, p<0.05)$. Due to the dominant role of leadership in organizational context, it is reasonable to believe that leadership is an important influence factor of work stress.

Ethical leadership is defined as "the demonstration of normatively appropriate conduct through personal actions and interpersonal relationships, and the promotion of such conduct to followers through two-way communication, reinforcement, and decision-making" (5). Ethical leadership involves exhibiting traits such as honesty and integrity, treating employees fairly, showing concern and respect for employees, establishing two-way communication characterized by trust and openness, encouraging employees to participate in decision-making, giving employees sufficient job autonomy, and adhering to people-oriented principle (6). As such, ethical leadership is generally regarded as an effective leadership style. For instance, Avey et al. (7) demonstrated that ethical leadership was positively related to employee psychological well-being and job satisfaction $(\beta=0.20, \mathrm{p}<0.01$; $\beta=0.38, \mathrm{p}<0.01$, respectively).

Considering the traits and appropriate conduct of ethical leaders, it can be predicted that ethical leadership would relieve employees' work stress. However, there is no empirical evidence for the link between ethical leadership and work stress. To fill this gap, the first purpose of this study is clarifying the effect of ethical leadership on work stress.

Judge and Colquitt (8), for example, found that procedural justice and interpersonal justice were both negatively associated with employees' work stress $(\beta=-0.21, \mathrm{p}<0.01 ; \beta=-0.13, \mathrm{p}<0.01$, respectively). By demonstrating fairness, ethical leaders provide a supportive context for employees to get rid of negative emotions, such as fear and anxiety, during the work (9). Correspondingly, employees' work stress is reduced.

What is more, ethical leaders highlight two-way communication, in which both leaders and employees can express their opinions freely. On one hand, it is beneficial for employees to clarify their responsibilities and recognize leaders' expectations (10). Previous research demonstrated that role ambiguity was a critical source of work stress (11). On the other hand, through two-way communication, employees are able to obtain supports from leaders. Leader supports have been proved negatively correlated with work stress $(r=-0.31, p<0.05)(12)$.

Ethical leaders usually provide employees with high-level job autonomy and job control, which is helpful for relieving work stress. Karasek (13) underlined the importance of job control in his job demands-control model, and found that job control was negatively related to employees' work stress $(\beta=-0.15, \mathrm{p}<0.001)$. Furthermore, Wong et al. (14) indicated that once employees 
obtained enough job control, work stress evoked by job demands would decrease drastically $(\beta=-0.39, \mathrm{p}<0.001)$.

Finally, as ethical leaders are people-oriented, they show concerns for subordinates and attach great importance to subordinates' developmental needs. It is helpful for relieving employees' work stress. For example, Sosik and Godshalk (15) confirmed that transformational leadership based on charisma and individual consideration was negatively related to employees' work stress $(\beta=-0.08, p<0.05)$. Based on the analysis mentioned above, we proposed that:

Hypothesis 1: Ethical leadership is negatively related to employees' work stress.

The second purpose of this study is examining the mediating role of leader-member exchange (LMX), which refers to the dyadic exchange relationships between supervisors and subordinates within the workplace (16). Wang et al. (17) indicated that the quality of leader-subordinate relationship was a fundamental link between leader behaviour and employee response. The coefficient of the path from transformational leadership to LMX was significant $(\beta=0.80, p<0.01)$, as were the coefficients of the paths from LMX to in-role performance $(\beta=0.16, p<0.05)$ and extra-role performance $(\beta=0.32, \mathrm{p}<0.01)$.

Existing literature has specified the positive correlations between ethical leadership and LMX. For example, Walumbwa et al. (18) found that ethical leadership was positively related to $\operatorname{LMX}(\beta=0.50, p<0.01)$, because ethical leaders concerned about employees' interests and personal growth. Besides, involving in two-way communication and decision-making, employees acquire job-related supports and further reinforce the relationships with their leaders (19). Brown et al. (5) carried out empirical research indicating that ethical leadership was positively associated with employees' trust in their leaders $(r=0.76, p<0.001)$, which was a key element of high-quality LMX (20). Therefore, integrity, honesty and fairness displayed by ethical leaders benefit the formation of trusting relationships with employees and result in strengthened LMX.

According to the job demands-resources model, work stress is evoked when an employee does not have enough job resources to meet job demands (21). Comparing with those in low-quality LMX, employees in high-quality LMX receive preferential treatment, performance feedback, and job-related communication, which can serve as job resources to reduce work stress (22). As such, it is reasonable to predict that LMX is negatively related to work stress. Based on the above analysis, we proposed that:

Hypothesis 2: LMX mediates the relationship between ethical leadership and employees' work stress.

The hypothesized model is shown in Figure 1.

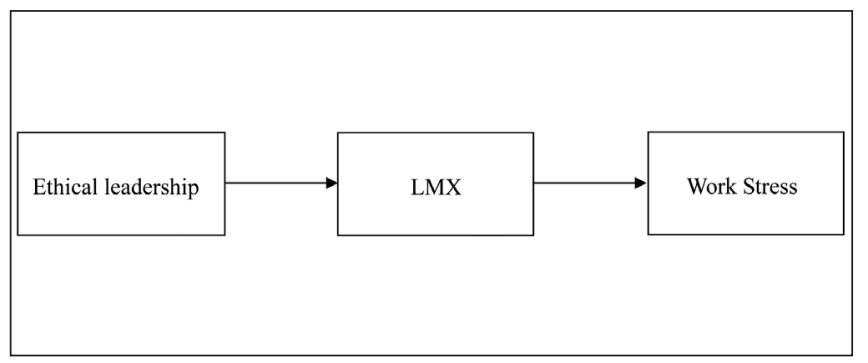

Fig. 1. Hypothesized model.

\section{MATERIALS AND METHODS}

\section{Sample and Procedures}

The data were collected from a communications enterprise located in China. 206 first-line technical support employees were invited to complete structured surveys during normal working hours. Double-blind design was adopted in this study. All participants took part in the study voluntarily. We received completed and usable questionnaires from 203 respondents. The successful return ratio was $98.5 \%$. Of the respondents, $58.6 \%$ were male. The average age was 35.24 years $(\mathrm{SD}=8.05)$ and the average number of years in the company and in current position were 13.67 years $(\mathrm{SD}=9.31)$ and 11.12 years $(\mathrm{SD}=8.29)$, respectively.

\section{Measures}

A questionnaire that included 47 multiple-choice questions and 3 open-ended questions was adopted in this study. We measured ethical leadership using the 10-item scale developed by Brown et al. (5). Ratings were made by respondents on a 7-point Likert scale, from 1 (very strongly disagree) to 7 (very strongly agree). A sample item is: "My supervisor sets an example of how to do things the right way in terms of ethics".

We measured LMX using the 7-item scale developed by Graen et al. (23). Respondents were asked to assess the quality of relationships with their supervisors on a 5-point Likert scale, from 1 (not at all) to 5 (to a very large extent). A sample item is "How well does your supervisor understand your job problems and needs?".

To measure employees' perception of work stress, we adopted the 28-item Stress Reaction Questionnaire (SRQ) developed by department of medical psychology in Zhejiang University. It has been widely used in the studies of Chinese employees' work stress. Respondents were asked to report their feelings of work stress, such as anxiety, fear, and anger on a 5-point Likert scale, from 1 (not at all) to 5 (to a very large extent). A sample item is: "During the past month, I always felt worried".

Following previous research on work stress, we asked for participations to report their age (years), gender $(0=$ male, 1 = female), years in the company, years in current position, and educational level $(1=$ middle school, $2=$ high school $/$ technical school, 3 = university/college, 4 = graduate school). We controlled these variables to partial out their influences on work stress.

\section{Analytic Strategy}

A series of hierarchical regression analyses were conducted to test our hypotheses. The mediating role of LMX was tested following Baron and Kenny's procedure (24). First, the independent variable should be significantly related to the dependent variable. Second, the independent variable should be significantly related to the mediator. Third, after including the mediating variable in the regression equation, the significant relationship between the independent variable and the dependent variable should disappear or substantially diminish. At the same time, the mediating variable should be related to the dependent variable. 


\section{RESULTS}

Means, standard deviations, and correlations were presented in Table 1. As we predicted, ethical leadership was negatively correlated with perception of work stress $(r=-0.37, p<0.01)$. Ethical leadership was positively related to $\operatorname{LMX}(\mathrm{r}=0.55, \mathrm{p}<0.01)$. We also found that LMX was negatively related to the perception of work stress $(\mathrm{r}=-0.35, \mathrm{p}<0.01)$.

Hierarchical regression analysis was conducted to test hypotheses 1. Control variables (age, gender, education, years in the company, and years in current position) were entered into the regression model firstly. And then, independent variable (ethical leadership) and mediator variable (LMX) were entered into the regression model. As shown in Table 2, after controlling the effects of control variables, ethical leadership was negatively related to the perception of work stress $(\beta=-0.24, p<0.001)$. Hypothesis 1 was supported.

The mediating role of LMX was tested following Baron and Kenny's procedure (24). As indicated above, ethical leadership was negatively related to employees' perception of work stress $(\beta=-0.24, p<0.001)$. As shown in Table 2, LMX was also negatively related to the perception of work stress $(\beta=-0.30$, $\mathrm{p}<0.001)$. Meanwhile, ethical leadership was positively related to $\operatorname{LMX}(\beta=0.59, \mathrm{p}<0.001)$. Finally, after including LMX in the regression equation, the significant effect of ethical leadership on perception of work stress disappeared $(\beta=-0.09$, ns), while LMX was significantly associated with perception of work stress $(\beta=-0.25, \mathrm{p}<0.001)$. In conclusion, LMX completely mediated the relationship between ethical leadership and perception of work stress. Hypothesis 2 was supported.

The result of this study is shown in Figure 2.

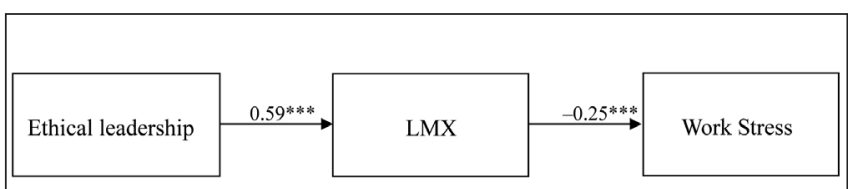

Fig. 2. Relationship between ethical leadership and work stress, ${ }^{* * *} p<0.001$.

\section{DISCUSSION}

Employees are experiencing high work stress in today's work environment. Work stress not only disorders employees physically and psychologically, but also disturbs organizations seriously. The primary goal of the present study was to extend prior work stress research by investigating the impact of ethical leadership on employees' perception of work stress. We built and tested a conceptual model in which ethical leadership influenced employees' perception of work stress through LMX. As expected, our results indicated that ethical leadership was negatively related to employees' perception of work stress, and this relationship was completely mediated by LMX. The implications and limitations of this study are discussed below.

Table1. Means, standard deviations, correlations, and reliabilities

\begin{tabular}{|l|c|c|c|c|c|c|c|c|c|c|}
\hline Variable & Mean & SD & $\mathbf{1}$ & $\mathbf{2}$ & $\mathbf{3}$ & $\mathbf{4}$ & $\mathbf{5}$ & $\mathbf{6}$ & $\mathbf{7}$ & $\mathbf{8}$ \\
\hline Age & 35.24 & 8.05 & - & & & & & & & \\
\hline Gender & 0.41 & 0.49 & -0.09 & - & & & & & & \\
\hline Educational level & 2.99 & 0.30 & -0.09 & 0.07 & - & & & & & \\
\hline Years in the company & 13.67 & 9.31 & $0.96^{* *}$ & -0.05 & -0.07 & - & & & & \\
\hline Years in current position & 11.12 & 8.29 & $0.71^{* *}$ & -0.10 & -0.03 & $0.74^{* *}$ & - & & & \\
\hline Ethical leadership & 5.71 & 0.59 & $-0.27^{* *}$ & 0.08 & 0.12 & $-0.21^{* *}$ & $-0.37^{* *}$ & $(0.95)$ & & \\
\hline LMX & 3.29 & 0.60 & -0.08 & -0.03 & $0.26^{* *}$ & -0.05 & -0.09 & $0.55^{* *}$ & $(0.95)$ & \\
\hline Perception of work stress & 1.76 & 0.55 & $0.70^{* \star}$ & 0.01 & $-0.18^{*}$ & $0.66^{* *}$ & $0.49^{* *}$ & $-0.37^{* *}$ & $-0.35^{* \star}$ & $(0.95)$ \\
\hline
\end{tabular}

$\mathrm{n}=203$, Internal consistency reliabilities are in parentheses, ${ }^{* *} \mathrm{p}<0.01,{ }^{*} \mathrm{p}<0.05 . \mathrm{LMX}-$ Leader-member exchange.

Table 2. Regression analysis results for mediation

\begin{tabular}{|l|c|c|c|c|}
\hline & LMX vs. Cv + EL & WS vs. Cv + EL & WS vs. Cv + LMX & WS vs. Cv + LMX + EL \\
\hline Age & 0.19 & $0.64^{* *}$ & $0.73^{* * *}$ & $0.69^{* * *}$ \\
\hline Gender & -0.06 & 0.07 & 0.05 & 0.06 \\
\hline Education & $0.20^{* *}$ & -0.10 & -0.04 & -0.05 \\
\hline Years in the company & -0.13 & 0.10 & 0.02 & 0.07 \\
\hline Years in current position & 0.08 & -0.14 & -0.09 & -0.12 \\
\hline Ethical leadership & $0.59^{* * *}$ & $-0.24^{* * *}$ & & -0.09 \\
\hline LMX & & & $-0.30^{* * *}$ & $-0.25^{* * *}$ \\
\hline$R^{2}$ & 0.36 & 0.60 & 0.60 \\
\hline Adjusted R & 0.34 & 0.56 & 0.58 & 0.58 \\
\hline F & $16.30^{* * *}$ & 0.54 & $41.98^{* * *}$ & $36.51^{* * *}$ \\
\hline
\end{tabular}

$n=203$, values are standardized coefficients, ${ }^{* * *} p<0.001,{ }^{* *} p<0.01 . L M X-$ Leader-member exchange, WS - Perception of work stress, Cv - Control variables, EL - Ethical leadership. 
First, this study made an initial attempt to explore the relationship between ethical leadership and employees' perception of work stress. According to our results, employees will be less stressed at work when their leaders demonstrate normatively appropriate conduct. In addition to exhibiting concern, ethical leaders can also help employees relieve work stress by presenting fair treatment, establishing two-way communication and providing sufficient job autonomy. Identifying ethical leadership as an effective remedy for work stress, we contribute to the work stress literatures.

Secondly, we selected LMX as the mediator to explain how ethical leadership affected employees' perception of work stress. The results of our study are congruent with previous research, pointing out a positive association between ethical leadership and LMX. Furthermore, employees might benefit from high-quality relationships with their ethical leaders, such as the reduction of work stress. Based on our study, it can be inferred that the relationships between leaders and subordinates were valuable resources to help employees cope with work stress.

Our study also has several practical implications. Due to the significant role of ethical leadership in decreasing employees' perception of work stress, organizations can take steps to encourage managers' ethical leadership. For example, organizations should emphasize the importance of moral identity when selecting managers. Organizations should invest in ethical leadership trainings and motivate managers to exhibit ethical behaviour by utilizing a variety of incentives. Measures of morality should be included into managers' performance appraisal, which influence managers' compensation and promotion. As shown in Table 1, employees' age, years in the company and years in current position are negatively related to their perceptions of ethical leadership. It means that, for those older and experienced employees, their standards for ethical leader are higher than junior employees'. Therefore, to improve ethical leadership, managers should pay more attention to the senior employees, such as making more efforts to improve two-way communication with them.

In addition, our results enable managers to understand the mechanism of the relationship between ethical leadership and employees' work stress. Employees' perception of work stress can be lessened if employees are involved in high-quality LMX. Thus, managers should build close relationships with their subordinates by promoting interpersonal interactions, showing trust, and providing developmental feedback.

There are several limitations of the present study. First, all variables in our study were self-reported, common method bias may be a threat to our conclusion. Future research should collect data from different sources. For example, it should be worth to measure work stress using physiological indicators, such as blood pressure. Secondly, cross-sectional design of this study prevented us from ascertaining the causal relationships between variables. Future research should use a longitudinal design to reconfirm the causal inferences found here. Third, data from a single organization may limit the generalizability of our findings. Future research should examine our results in other organizational settings. The last but not least important, we did not take work performance into consideration in this study. The future study can construct a comprehensive model to examine the relationship between ethical leadership, work stress, and work performance.

\section{Acknowledgement}

This study was funded by The National Natural Science Foundation of China (71472129, 71002047, 71001075), and by Sichuan University (skqx201503, skqx201112).

\section{Conflict of Interest}

None declared

\section{REFERENCES}

1. Ivancevich JM, Matteson MT, Preston C. Occupational stress, type A behavior, and physical well being. Acad Manage J. 1982 Jun;25(2):37391.

2. Stress out? A study of trends in workplace stress across the globe [Internet]. Regus; 2009 [cited 2014 Dec 20]. Available from: http://www.regus. cn/images/Stress\%20full\%20report FINAL Designed tcm307-21560. pdf.

3. Zhang Y, LePine JA, Buckman BR, Wei F. It's not fair...or is it? The role of justice and leadership in explaining work stressor-job performance relationships. Acad Manage J. 2014 Jun;57(3):675-97.

4. Tang CS, Au WT, Schwarzer R, Schmitz G. Mental health outcomes of job stress among Chinese teachers:role of stress resource factors and burnout. J Organ Behav. 2001 Dec;22(8):887-901.

5. Brown ME, Treviño LK, Harrison DA. Ethical leadership: a social learning perspective for construct development and testing. Organ Behav Hum Decis Process. 2005 Jul;97(2):117-34.

6. Mayer DM, Aquino K, Greenbaum RL, Kuenzi M. Who displays ethical leadership, and why does it matter? An examination of antecedents and consequences of ethical leadership. Acad Manag J. 2012 Feb;55(1):15171.

7. Avey JB, Wernsing TS, Palanski ME. Exploring the process of ethical leadership: the mediating role of employee voice and psychological ownership. J Bus Ethics. 2012 Apr;107(1):21-34.

8. Judge TA, Colquitt JA. Organizational justice and stress: the mediating role of work-family conflict. J Appl Psychol. 2004 Jun;89(3):395-404.

9. George JM, Zhou J. Dual tuning in a supportive context: joint contributions of positive mood, negative mood, and supervisory behaviors to employee creativity. Acad Manag J. 2007 Jun;50(3):605-22.

10. De Hoogh AHB, Den Hartog DN. Ethical and despotic leadership, relationships with leader's social responsibility, top management team effectiveness and subordinates' optimism:a multi-method study. Leadersh Q. 2008 Jun;19(3):297-311.

11. Tubre TC, Collins JM. Jackson and Schuler (1985) revisited: a metaanalysis of the relationships between role ambiguity, role conflict and job performance. J Manag. 2000 Feb;26(1):155-69.

12. Lee RT, Ashforth BE. A meta-analytic examination of the correlates of the three dimensions of job burnout. J Appl Psychol. 1996 Apr;81(2):123-33.

13. Karasek R. Job demands, job decision latitude, and mental strain: implications for job redesign. Adm Sci Q. 1979 Jun;24(2):285-306.

14. Wong SS, DeSanctis G, Staudenmayer N. The relationship between task interdependency and role stress:a revisit of the job demands - control model. J Manag Stud. 2007 Mar;44(2):284-303.

15. Sosik JJ, Godshalk VM. Leadership styles, mentoring functions received, and job-related stress:a conceptual model and preliminary study. J Organ Behav. 2000 Jun;21(4):365-90.

16. Liden RC, Erdogan B, Wayne SJ, Sparrowe RT. Leader-member exchange, differentiation, and task interdependence: implications for individual and group performance. J Organ Behav. 2006 Sep;27(6):723-46.

17. Wang H, Law SK, Hackett RD, Wang D, Chen ZX. Leader-member exchange as a mediator of the relationship between transformational leadership and followers' performance and organizational citizenship behavior. Acad Manag J. 2005 Jun;48(3):420-32.

18. Walumbwa FO, Mayer DM, Wang P, Wang H, Workman K., Christensen AL. Linking ethical leadership to employee performance: the roles of leader-member exchange, self-efficacy, and organizational identification. Organ Behav Hum Decis Process. 2011 Jul;115(2):204-13.

19. Erdogan B, Liden RC, Kraimer ML. Justice and leader-member exchange: the moderating role of organizational culture. Acad Manag J. 2006 Apr;49(2):395-406. 
20. Graen GB, Uhl-Bien M. Relationship-based approach to leadership: development of leader-member exchange theory of leadership over 25 years: applying a multi-level multi-domain perspective. Leadersh Q. 1995 Jan;6(2):219-47.

21. Bakker AB, Demerouti E. The job demands-resources model: state of the art. J Manag Psychol. 2007 Apr;22(3):309-28.

22. Elicker JD, Levy PE, Hall RJ. The role of leader-member in the performance appraisal process. J Manage. 2006 Aug;32(4):531-51.

23. Graen G, Novak MA, Sommerkamp P. The effects of leader-member exchange and job design on productivity and satisfaction: testing a dual attachment model. Organ Behav Hum Perform. 1982 Aug;30(1):109-31.
24. Baron RM, Kenny DA. The moderator-mediator variable distinction in social psychological research: conceptual, strategic, and statistical considerations. J Pers Soc Psychol. 1986 Dec;51(6):1173-82.

Received January 6, 2015 Accepted in revised form April 13, 2015 